\title{
Research on the Values of Amplitudes of Electrocar- diographic Waves Depending on Age in Kids
}

\author{
Dragos Corneliu COTOR ${ }^{1}$, Gabriel GAJAILA ${ }^{2}$, Aurel DAMIAN ${ }^{1}$, Ana Maria ZAGRAI (Maierean) ${ }^{1}$, Carmen \\ PETCU $^{2}$, Simona CALIN (Nicolae) ${ }^{2}$, Adrian RADUTA², Crina ANDREI ${ }^{2}$, Gavrilă ZAGRAI ${ }^{2 *}$ \\ ${ }^{1}$ Faculty of Veterinary Medicine, University of Agricultural Sciences and Veterinary Medicine of Cluj-Napoca \\ ${ }^{2}$ Faculty of Veterinary Medicine, University of Agricultural Sciences and Veterinary Medicine Bucharest \\ *Corresponding author: gavrilazag@yahoo.com
}

Bulletin UASVM Veterinary Medicine 77(2)/2020

Print ISSN 1843-5270; Electronic ISSN 1843-5378

doi:10.15835/buasvmcn-vm:2020.0019

\begin{abstract}
The electrocardiogram (ECG) is a graphical recording of the cardiac electric activity during cardiac revolutions. This bio-current triggers and maintains the mechanical activity of the heart. Within this research, the amplitudes values of the electrocardiographic waves were determined in 6 leads: I, II, III, aVL, aVR and aVF. Thus, some electrocardiograms were recorded using limb lead in clinically healthy kids, aged 1 month, 3 months and 5 months, in order to achieve the proposed objectives. Then, the statistical analysis of the obtained results was performed using $\mathrm{t}$ (student) test.

As a consequence of the interpretation of the obtained results, it was noticed that the limb leads can be used successfully for recording the electrocardiogram in kids because it provides an easy aspect to interpret. The highest amplitude of the electrocardiographic waves is recorded in I lead, in the case of the 1 month old kids (having the following values: $0.115 \mathrm{mV} \pm 0.010$ for P wave; $0.625 \mathrm{mV} \pm 0.078$ for QRS complex; $0.460 \mathrm{mV} \pm 0.045$ for $\mathrm{T}$ wave) and in II lead (having the following values for the 3 months old kids: $0.071 \mathrm{mV} \pm 0.015$ for P wave; $0.540 \mathrm{mV} \pm$ 0.064 for QRS complex; $0.310 \mathrm{mV} \pm 0.052$ for $\mathrm{T}$ wave and having the following values for the 5 months old kids: $0.071 \mathrm{mV} \pm 0.015$ for P wave; $0.455 \mathrm{mV} \pm 0.028$ for QRS complex; $0.430 \mathrm{mV} \pm 0.026$ for $\mathrm{T}$ wave). It also found that the lowest amplitude of electrocardiographic waves is recorded in the aVF lead, but this lead cannot be used for ECG recording in kids.
\end{abstract}

Keywords: amplitude, electrocardiogram, derivation, kid

\section{Introduction}

The electrocardiogram is a non-invasive diagnosis method that assesses the electric activity of the heart. It provides certain information related to a clinically healthy heart, such as excitement system integrity, duration and frequency of atrial and ventricular systole, but also related to heart diseases such as rhythm disorders or the effect of some substances on the heart (Brăslașu et al., 2015). Although the method is not very new, nowadays, it is one of the most used methods for investigating heart activity (Ghiță et al., 2007).
The electrocardiogram has great importance in practice and is recommended for calculating heart rate, determining heart rhythm and calculating the duration (for waves, segments and intervals) and the amplitudes (for waves) of electrocardiographic components (Ghiță et al., 2016). It can also be used to determine the cardiac electrical axis (Ghiță et al., 2007).

Regarding the veterinary medicine, the electrocardiogram is extensively used in small animal practice, but in the literature, there are numerous studies on dogs, cats and horses. 
Currently, there is limited literature related to the use of electrocardiogram in kids (Atmaca et al., 2014, Fakour et al., 2013, Ghiță et al., 2019, Ghiță et al., 2016, Jafrin et al., 2016, Pogliani et al., 2013). This topic has not been yet studied in our country.

The current study focused on recording electrocardiograms of kids of different ages (1 month, 3 and 5 months-old ones), using the limb derivations in order to determine the values of the P, QRS and T wave amplitudes, especially how these values are changing in relation to the age. Studying the literature, there were found very few researches on this topic, most of the authors being from Asia (where the interest in growing this species is higher).

\section{Methods and materials}

It was used a portable electrocardiograph INNOMED HEART MIRROR, in the current research. The electrodes were equipped with alligator catchers and alcohol was the contact medium between the animal's skin and the electrodes.
All electrocardiograms were recorded using limb leads. So, the electrodes were placed as follows: the red electrode on the right foreleg, the yellow electrode on the left foreleg, the green electrode on the right hind leg and the black electrode on the right hind leg.

The working parameters used were the speed of paper of $25 \mathrm{~mm} / \mathrm{sec}$ and the amplitude of the millivolt of $10 \mathrm{~mm}$.

The statistical analysis of the obtained results was performed using the $t$ (student) test (Excel).

\section{Results and discussions}

The values of the average amplitudes of the $P$ wave, in kids in relation to age are presented in Table 1 and in Figure 1.

Regarding the P wave (Table 1 and Figure 1), it is observed that in the case of 1-month old kids, it has a maximum average amplitude in D I, with the average value of $0.115 \mathrm{mV}$ and the standard deviation is $0.033 \mathrm{mV}$. Comparing the values from this study to the values obtained in the case of 3

Table 1. Amplitude of $\mathrm{P}$ wave (mV) in kids, depending on age (mean and standard deviation)

\begin{tabular}{ccccccc}
\hline Age & D I & D II & D III & aVR & aVL & aVF \\
\hline 1 month & $\mathbf{0 . 1 1 5} \pm \mathbf{0 . 0 3 3}$ & $0.052 \pm 0.032$ & $0.055 \pm 0.049$ & $0.065 \pm 0.041$ & $0.071 \pm 0.048$ & $0.035 \pm 0.024$ \\
\hline 3 months & $0.054 \pm 0.032$ & $\mathbf{0 . 0 7 1} \pm \mathbf{0 . 0 1 5}$ & $0.067 \pm 0.021$ & $0.055 \pm 0.012$ & $0.021 \pm 0.012$ & $0.038 \pm 0.011$ \\
\hline 5 months & $0.044 \pm 0.011$ & $\mathbf{0 . 0 7 1} \pm \mathbf{0 . 0 1 5}$ & $0.058 \pm 0.023$ & $0.061 \pm 0.022$ & $0.032 \pm 0.018$ & $0.041 \pm 0.014$ \\
\hline
\end{tabular}

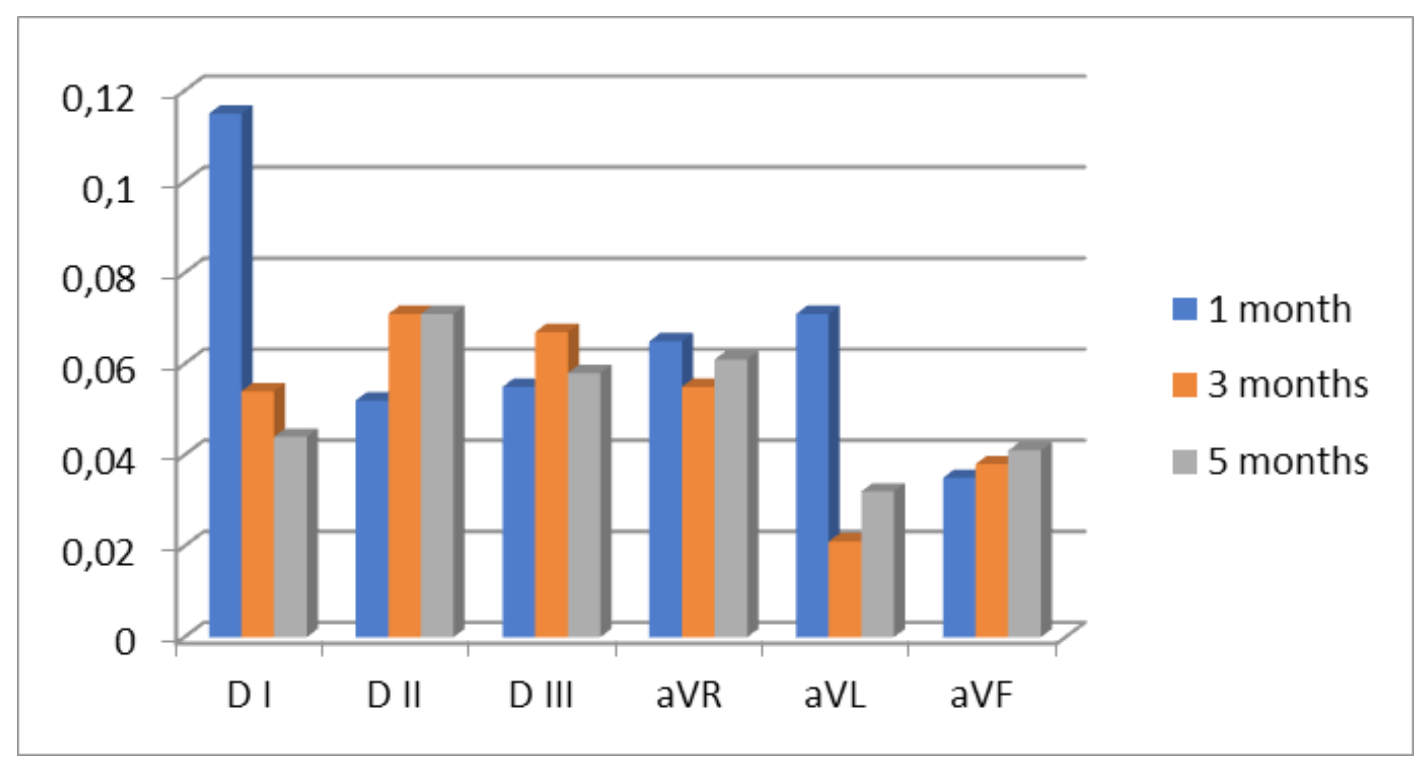

Figure 1. The average amplitude of the $\mathrm{P}$ wave in kids, depending on age 
and 5 month old kids, it is observed that in the case of 1 month old kids, the average amplitude of the P wave recorded in D I is $112.96 \%$ higher than the average value recorded in the case 3-month-old kids and $161.36 \%$ higher compared to the average value registered in the case of 5-month-old kids. In both circumstances, the noted differences were statistically distinctly significant $(\mathrm{p}<0.01)$.

In the case of 3 and 5 -month old kids, the maximum amplitude of the $\mathrm{P}$ wave is registered in D II (in both situations the average value is $0.071 \mathrm{mV}$ and the standard deviation is 0.015 $\mathrm{mV}$ ). Comparing the value from this research to the value obtained in the case of 1-month-old kids, it is observed that it is $36.53 \%$ higher and the difference is significant $(\mathrm{p}<0.1)$.

In all studied group, the lowest amplitude of the $\mathrm{P}$ wave is recorded in the AVF derivation.

Some other authors (Atmaca et al., 2014, Ghița et al., 2008, Pradhan et al., 2017) recommend only the use of the D II derivation, motivating that this derivation gives the highest amplitude to the $\mathrm{P}$ wave. But the current study demonstrates that the P wave's highest amplitude in 1-month old kids' group, was registered in D I, while for the other two study groups, the results were similar to the ones described in the literature.

Regarding the QRS complex (Tab 2 and Fig 2), it is observed that its highest amplitude is also recorded in D I, in the case of 1-month-old kids, with an average value of $0.625 \mathrm{mV}$ and a standard deviation of $0.078 \mathrm{mV}$. The obtained value is $48.45 \%$ higher compared to the value registered in the case of 3-month-old kids, and $52.06 \%$ higher compared to the value registered in the case of 5-month-old kids. In both situations, the differences found are distinctly significant $(\mathrm{p}<0.01)$.

In the case of 3-month-old kids, the highest amplitude of the ventricular complex is recorded in DII with an average value of $0.540 \mathrm{mV}$ and a standard deviation of $0.064 \mathrm{mV}$. The obtained value is $18.68 \%$ higher than the value registered in the case of 5 -month-old kids (insignificant difference: $\mathrm{p}<0.5$ ) and $24.08 \%$ higher than the value

Table 2. Amplitude of the QRS (mV) in kids, depending on age (mean and standard deviation)

\begin{tabular}{ccccccc}
\hline \multicolumn{1}{c}{ Age } & D I & D II & D III & aVR & aVL & aVF \\
\hline 1 month & $\mathbf{0 . 6 2 5} \pm \mathbf{0 . 0 7 8}$ & $0.441 \pm 0.012$ & $0.521 \pm 0.034$ & $0.238 \pm 0.042$ & $0.599 \pm 0.031$ & $0.228 \pm 0.024$ \\
\hline 3 months & $0.421 \pm 0.023$ & $\mathbf{0 . 5 4 0} \pm \mathbf{0 . 0 6 4}$ & $0.520 \pm 0.025$ & $0.332 \pm 0.021$ & $0.511 \pm 0.021$ & $0.312 \pm 0.011$ \\
\hline 5 months & $0.411 \pm 0.032$ & $\mathbf{0 . 4 5 5} \pm \mathbf{0 . 0 2 8}$ & $0.422 \pm 0.031$ & $0.291 \pm 0.032$ & $0.441 \pm 0.041$ & $0.218 \pm 0.018$ \\
\hline
\end{tabular}

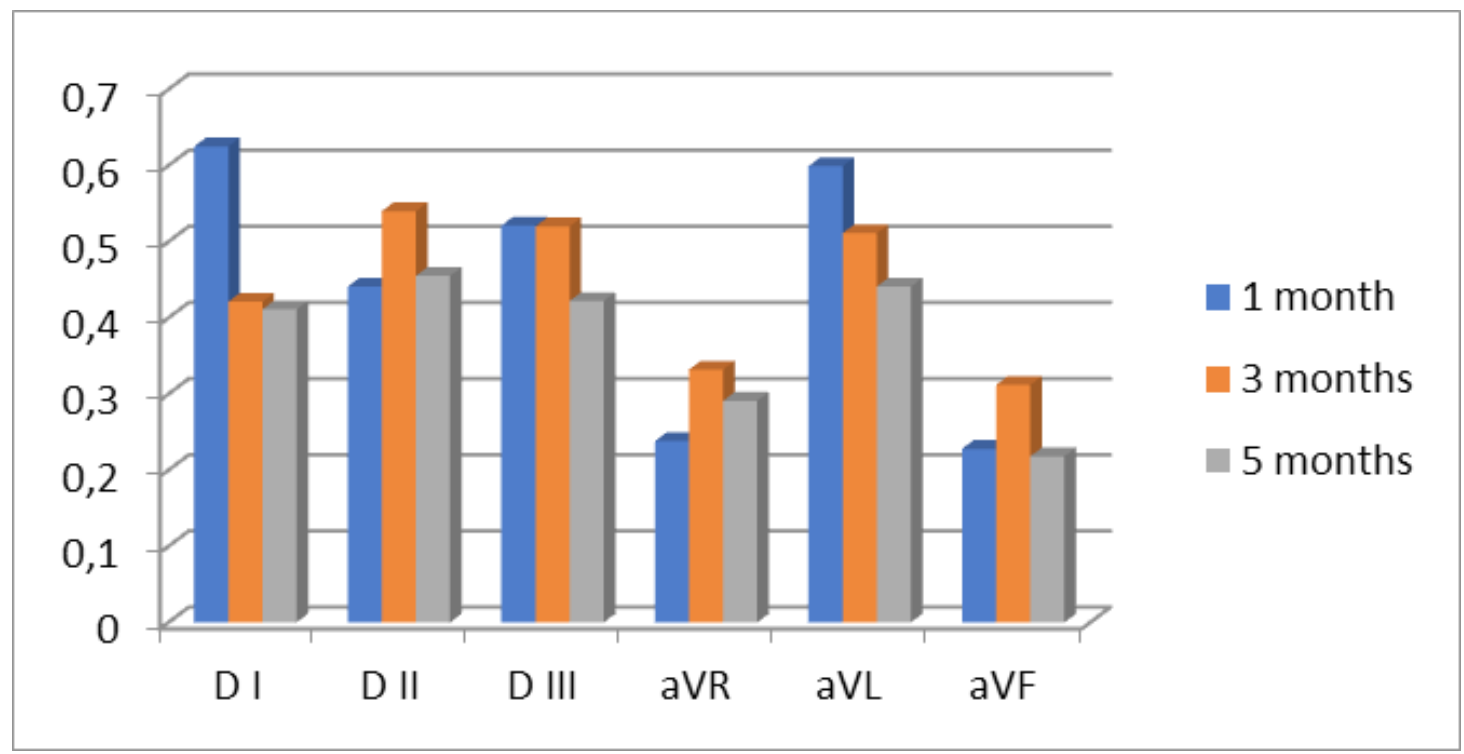

Figure 2. The average amplitude of the QRS complex in kids, depending on age 
registered in the case of 1-month-old kids (significant difference: $\mathrm{p}<0.1$ ).

In the case of 5-month-old kids, the highest amplitude of the ventricular complex is recorded in DII with an average value of $0.544 \mathrm{mV}$ and a standard deviation of $0.028 \mathrm{mV}$. The obtained value is $10.70 \%$ higher than the value registered in the case of 1-month-old kids, but $15.74 \%$ lower than in the case of 3-month-old kids. In both situations the differences found are insignificant $(\mathrm{p}<0.5)$.

The current results are similar to the results communicated by other authors (Ghiță et al., 2019, Pogliani et al., 2013) who recommend only the use of the DII derivation, motivating that this derivation confers the highest amplitude to the ventricular complex. A possible explanation may be the change in the topography of the heart in the rib cage or rather the development of the left ventricle with aging, because blood pressure in the left ventricle is higher than in the right ventricle, which determines a greater development.
Regarding the T wave (Table 3 and Figure 3), its highest amplitude is observed in D I, with an average of $0.460 \mathrm{mV}$ and the standard deviation is $0.045 \mathrm{mV}$.

The obtained value is $57.82 \%$ higher compared to the value registered in the case of 3-month-old kids (significant difference) $(\mathrm{p}<0.1)$ and $17.34 \%$ higher compared to the value registered in the case of 5-month-old kids (insignificant difference) $(\mathrm{p}<0.5)$.

In the case of 3-month-old kids, the highest amplitude of the $\mathrm{T}$ wave is recorded in DII with an average value of $0.310 \mathrm{mV}$ and a standard deviation of $0.052 \mathrm{mV}$.

The obtained value is $18.63 \%$ lower than the value registered in the case of 1 -month-old kids, and $27.90 \%$ lower than the value registered in the case of 5-month-old kids, both differences being insignificant $(\mathrm{p}<0.5)$.

In the case of 5-month-old kids, the highest amplitude of the $\mathrm{T}$ wave is recorded in DII with

Table 3. Amplitude of T wave (mV) in kids, depending on age (mean and standard deviation)

\begin{tabular}{lcccccc}
\hline \multicolumn{1}{c}{ Age } & D I & D II & D III & aVR & aVL & aVF \\
\hline 1 month & $\mathbf{0 . 4 6 0 \pm 0 . 0 4 5}$ & $0.381 \pm 0.032$ & $0.411 \pm 0.029$ & $0.317 \pm 0.052$ & $0.442 \pm 0.033$ & $0.221 \pm 0.038$ \\
\hline 3 months & $0.290 \pm 0.042$ & $\mathbf{0 . 3 1 0 \pm 0 . 0 5 2}$ & $0.281 \pm 0.031$ & $0.180 \pm 0.036$ & $0.300 \pm 0.026$ & $0.200 \pm 0.026$ \\
\hline 5 months & $0.392 \pm 0.052$ & $0.430 \pm \mathbf{0 . 0 2 6}$ & $0.419 \pm 0.043$ & $0.152 \pm 0.027$ & $0.425 \pm 0.035$ & $0.172 \pm 0.045$ \\
\hline
\end{tabular}

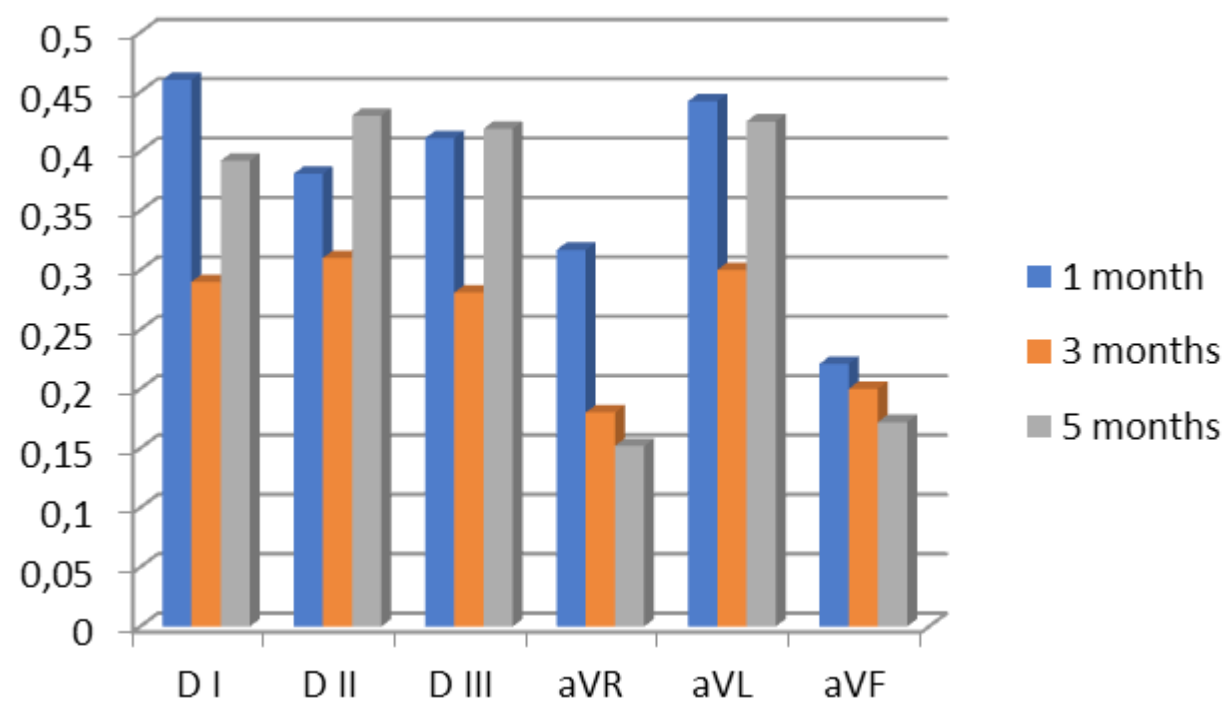

Figure 3. The average amplitude of $\mathrm{T}$ wave in kid, depending on age 
an average value of $0.430 \mathrm{mV}$ and a standard deviation of $0.026 \mathrm{mV}$.

The obtained value is $12.86 \%$ higher than the value registered in the case of 1-month-old kids, and $38.70 \%$ higher than in the case of 3-monthold kids. In both situations the differences are significant $(\mathrm{p}<0.1)$. The results of the current study confirm a greater development of the left ventricular myocardium, its repolarization generating a higher intensity bio current with aging.

The obtained values in this study, regarding $\mathrm{T}$ wave, fall within the limits of the values communicated by other authors (Ghița et al., 2019, Pradhan et al., 2017, Pogliani et al., 2013).

Analyzing the data regarding the values of the amplitudes of the electrocardiographic waves recorded in kids of different ages, we find the following:

- in the case of 1-month-old kids, the highest amplitude of electrocardiographic waves was recorded in DI, with average values of 0.115 $\pm 0.033 \mathrm{mV}$ in the case of the P wave, $0.625 \pm$ $0.078 \mathrm{mV}$ in the case of the QRS complex and $0.460 \pm 0.045 \mathrm{mV}$ in the case of the $\mathrm{T}$ wave;

- in the case of 3-month-old kids, the highest amplitude of electrocardiographic waves was recorded in DII with values of $0.071 \pm 0.015$ in the case of the P wave, $0.540 \pm 0.064 \mathrm{mV}$ in the case of the QRS complex and $0.310 \pm 0.052 \mathrm{mV}$ in the case of the T wave;

- in the case of 5-month-old kids, the highest amplitude of electrocardiographic waves was recorded in DII, with values of $0.071 \pm 0.015 \mathrm{mV}$ in the case of the $\mathrm{P}$ wave, $0.455 \pm 0.028 \mathrm{mV}$ in the case of the QRS complex and $0.430 \pm 0.026$ $\mathrm{mV}$ in the case of the $\mathrm{T}$ wave.

Comparing the values obtained in the current study to those presented by different authors (Atmaca et al., 2014, Fakour et al., 2013, Ghită et al., 2019, Jafrin et al., 2016, Pradhan et al., 2017, Pogliani et al., 2013) it is found that they fall within the values mentioned in the literature, especially in terms of the amplitude of electrocardiographic waves.

\section{Conclusions}

Limb leads can be used successfully to record the electrocardiogram in kids. In the case of 1-month-old kids, the highest amplitude of electrocardiographic waves is recorded in the DI derivation. In the case of 3- and 5-months old kids, the highest amplitude of the electrocardiographic waves is registered in the DII derivation. The lowest amplitude of electrocardiographic waves is recorded in the aVF derivation, for all age categories.

Acknowledgments. This research did not receive any specific grant from funding agencies in the public, commercial, or not-for-profit sectors.

\section{References}

1. Atmaca N, Şimşek O, Emre B (2014). Some electrocardiographic values of Angora goats. Faculty of Veterinary Medicine, Department of Physiology, Ankara Üniv Vet Fak Derg, 61, 15-19.

2. Brăslașu MC, Brăslașu DE, Simiz F, Ghiță M, Tudor P, Cotor G (2015). Electrocardiografic studies on adult cattle. Journal of Biotechnology, 208(Suppl.), S90).

3. Fakour S, Mokhber DMR, Nadalian MG, Rezakhani A, Lotfollah ZS (2013). Electrocardiographic parameters of Markhoz goat using base apex lead and six standard limb leads, Iranian Journal of Veterinary Research, 14(3):241244.

4. Ghiță M, Cotor G, Popescu D, Călin NS (2019). Research on the amplitudes of electrocardiographic waves in kids. Revista Română de Medicină Veterinară, 29(4):62-66.

5. Ghiță M, Cotor G, Bălăceanu R, Tobă LG (2016). Determination of values of the electrocardiogram's main components registered on calves at different ages. Scientific Works. Series C. Veterinary Medicine, LXII(2):34-37.

6. Ghiţă M, Cotor G, Brăslaşu M (2008). The values of ECG parameters in new born calves. Bulletin USAVM ClujNapoca, 65 (1): 473.

7. Ghiţă M, Cotor G, Brăslaşu C, Botezatu R (2007). Researches on the variation of the Mean Electrical Axis in dogs depending on the recording pozition, Lucrari Ştiinţifice Medicină Veterinară, Timişoara, XL:389-392.

8. Ghiță M, Cotor G, Brăslașu C, Botezatu R (2007). Studies on the duration of some ECG parameters in cats. Lucrari Ştiinţifice Medicicină Veterinară Timişoara, XL:393-396.

9. Jafrin AA, Nawab N, Anand KP (2016). The normal electrocardiogram of non-migratory bakarwali goats. Bhartiya Krishi Anushandhan Patrika, 31(1):69-73.

10. Pradhan RR, Mohapatra APK, Mohapatra S, Jyotiranjan T, Kundu AK (2017). Electrocardiographic reference values and configuration of electrocardiogram waves recorded in Black Bengal goats of different age groups, Veterinary World, EISSN: 2231-0916, 1020-1025

11. Pogliani FC, Birgel JEH, Monteiro BM, José HH, Raimondo FS (2013). The normal electrocardiogram in the clinically healthy Saanen goats. Pesq. Vet. Bras. 33(12):1478-1482. 